\title{
Leptin Aggravates Reflux Esophagitis by Increasing Tissue Levels of Macrophage Migration Inhibitory Factor in Rats
}

\author{
Tsugihiro Murata, ${ }^{1}$ Kiyotaka Asanuma, ${ }^{1}$ Nobuyuki Ara, ${ }^{1}$ Katsunori Iijima, ${ }^{2}$ \\ Waku Hatta, ${ }^{1}$ Shin Hamada, ${ }^{1}$ Naoki Asano, ${ }^{1}$ Tomoyuki Koike, ${ }^{1}$ Akira Imatani, ${ }^{1}$ \\ Atsushi Masamune ${ }^{1, *}$ and Tooru Shimosegawa, ${ }^{1, *}$ \\ ${ }^{1}$ Division of Gastroenterology, Tohoku University Graduate School of Medicine, Sendai, Miyagi, Japan \\ ${ }^{2}$ Department of Gastroenterology and Neurology, Akita University Graduate School of Medicine, Akita, Akita, \\ Japan
}

Leptin, produced primarily by the adipose tissue, acts as a pro-inflammatory modulator, thereby contributing to the development of obesity-related disease. Although high levels of leptin in the obese are closely related to gastroesophageal reflux disease, the mechanism by which leptin influences esophageal inflammation remains unknown. Macrophage migration inhibitory factor (MIF) is produced by immune cells, such as T lymphocytes and macrophages, and MIF is known to induce the production of tumor necrosis factor $\alpha$ (TNF- $\alpha)$, interleukin $1 \beta(\mathrm{IL}-1 \beta)$ and interleukin 6 (IL-6). We therefore investigated the mechanism whereby leptin aggravates reflux esophagitis, by focusing on esophageal tissue levels of MIF and CD3+ T lymphocytes, both of which are crucial for the reflux-induced epithelial damage. Esophageal inflammation was surgically induced in male Wistar rats by ligating the forestomach and narrowing the duodenum to facilitate gastroesophageal reflux, followed by administration of leptin or vehicle with an osmotic pump system for 1 week. We demonstrated that the administration of leptin exacerbated the reflux esophagitis with the apparent infiltration of CD3+ T lymphocytes and caused the significant increase in the esophageal tissue levels of MIF. Moreover, the leptin caused increases in the esophageal tissue levels of TNF- $\alpha$, IL-1 $\beta$ and IL-6, downstream targets of MIF. Importantly, the increases in these pro-inflammatory cytokines were accompanied by increased protein levels of phospho-STAT3 and phospho-AKT, pivotal molecules of leptin signaling pathways. In conclusion, through enhancing the MIF-induced inflammatory signaling, leptin could contribute to the development of gastroesophageal reflux disease.

Keywords: CD3+ T lymphocytes; leptin; macrophage migration inhibitory factor; obesity; reflux esophagitis Tohoku J. Exp. Med., 2018 May, 245 (1), 45-53. C 2018 Tohoku University Medical Press

\section{Introduction}

Obesity is a major risk factor for gastroesophageal reflux diseases (GERD) (Rubenstein et al. 2013). Epidemiologic studies have revealed a strong positive correlation between obesity and the disease progression in GERD from erosive reflux esophagitis to esophageal adenocarcinoma that arises from Barrett's esophagus, a condition in which columnar metaplastic epithelium replaces esophageal squamous epithelium damaged by gastric reflux (Corley et al. 2007; Spechler and Souza 2014). No single factor, however, accounts for the mechanism that promotes the disease progression.

Leptin, an obesity-related cytokine, is secreted mainly by adipocytes and its plasma levels are elevated in the obese (Zhang et al. 1994). In addition to the regulation of food intake and energy expenditure, leptin is associated with low-grade chronic inflammation, a pivotal feature of obesity, and it promotes the production of pro-inflammatory cytokines, such as tumor necrosis factor $\alpha$ (TNF- $\alpha$ ), interleukin $1 \beta$ (IL-1 $\beta$ ) and interleukin 6 (IL-6) (Iikuni et al. 2008). This immunomodulatory function of leptin is achieved through its binding to a cell surface leptin receptor (Ob-R), a single transmembrane domain receptor of the cytokine family (Iikuni et al. 2008). Although several isoforms of $\mathrm{Ob}-\mathrm{R}$ that have a common extracellular ligandbinding domain have been identified (Chua et al. 1997), only a long leptin receptor isoform $(\mathrm{Ob}-\mathrm{Rb})$ contains intracellular motifs required for the full activation of STAT3 and AKT signaling pathway, which is associated with an increase in pro-inflammatory cytokines (Carino et al. 2008; Wang et al. 2011). Several studies revealed that the inflam-

Received January 29, 2018; revised and accepted April 18, 2018. Published online May 15, 2018; doi: 10.1620/tjem.245.45.

*Senior authors.

Correspondence: Kiyotaka Asanuma, Division of Gastroenterology, Tohoku University Graduate School of Medicine, 1-1 Seiryo-machi, Aoba-ku, Sendai, Miyagi 980-8574, Japan.

e-mail: takaxeve2004@ aurora.ocn.ne.jp 
matory milieu related to leptin leads to the development of obesity-related morbidities such as cardiovascular disease and rheumatoid arthritis as well as the aggravation of infectious diseases (Otero et al. 2006; Singh et al. 2007).

Chronic inflammation in the obesity-related condition also influences gastrointestinal diseases through immune responses modulated by adipose-derived hormones (Yarandi et al. 2011). Previous studies demonstrated that leptin is associated with the development or aggravation of chronic hepatitis and inflammatory bowel disease through the activation of T lymphocytes (Siegmund et al. 2002; Fantuzzi et al. 2005). Moreover, an epidemiologic study demonstrated that the increased levels of leptin in the obese are closely associated with the development of Barrett's esophagus (Kendall et al. 2008). However, there is no study to clarify the mechanism whereby leptin signaling is involved in the development of esophageal columnar metaplasia.

Recently, macrophage migration inhibitory factor (MIF) was reported to play a pivotal role in the development of obesity-related diseases (Morrison and Kleemann 2015). Immune cells, including $T$ lymphocytes and macrophages, produce MIF that in turn induces the production of TNF- $\alpha$, IL- $1 \beta$ and IL-6 (Onodera et al. 2000; Chuang et al. 2010). We previously demonstrated that severe reflux esophagitis was accompanied by an increase in the esophageal tissue levels of MIF (Masaka et al. 2013). Additionally, a previous study demonstrated that the enhanced infiltration of $\mathrm{CD} 3+\mathrm{T}$ lymphocytes into the esophagus was associated with the development of esophageal damage caused by GERD (Souza et al. 2009). In the current study, we examined the role of leptin in reflux esophagitis, focusing on esophageal tissue MIF and CD3 + T lymphocytes to clarify the mechanism, by which obesity increases the risk of GERD.

\section{Methods}

Animals

In total, 30 Male Wistar rats (CLEA Japan, Tokyo, Japan) at 10-12 weeks old were used in the following experiments. All rats were acclimatized for 1 or 2 weeks before the experiments with free access to water and normal chow (CE2; CLEA Japan). The 20 rats were subjected to surgery to induce reflux esophagitis, and the other 10 rats were subjected to the sham surgery. The approval of the Animal Welfare Committee at Tohoku University Graduate School of Medicine was obtained for this study (article number: 2017 medicine animal-144).

\section{Reflux esophagitis model}

The reflux esophagitis was surgically induced according to the method reported by Omura et al. (1999). In brief, after overnight fasting, rats were anesthetized by inhalation of isoflurane (Wako, Osaka, Japan) and weighed (at day 0 ). Then, the proximal duodenum was narrowed by wrapping it with a 2-mm-wide cross sectional $18 \mathrm{Fr}$. Nelaton catheter (Sapheed; Terumo, Tokyo, Japan), and the non-glandular fore-stomach was bound by ligation with a 4-0 silk suture thread to facilitate the reflux of gastric acid into the esophagus. Following overnight deprivation of food and drinking water, all rats were provided with tap water and normal chow (CE-2). The food intake and water consumption were monitored every other day from day 3 to day 7 and calculated as the volume ( $\mathrm{g}$ or $\mathrm{mL}$ ) per 100 g-body weight $(\mathrm{BW}) /$ day.

\section{Experimental protocol}

After the acid-reflux induction surgery, 10 of the 20 rats were randomly selected to undergo continuous administration of leptin (a daily dose of $0.6 \mathrm{mg} / \mathrm{Kg}$-weight) for 1 week, according to a previous study (Barbier et al. 2001). The recombinant rat leptin protein (R\&D systems, Minneapolis, MN, USA) was dissolved in $200 \mu \mathrm{L}$ of $10 \mathrm{mM}$ phosphate buffered saline (PBS) solution and administered with a subcutaneously implanted ALZET osmotic pump, Model 2001 (ALZET, Cupertino, CA, USA). The other 10 rats with the reflux induction surgery underwent the subcutaneous implantation but with the osmotic pump containing only the vehicle $(200 \mu \mathrm{L}$ of $10 \mathrm{mM}$ PBS). In each group, 5 to 7 rats completed the experimental protocols of the present study. Additionally, among 10 rats with sham surgery, 5 rats received leptin and the others, vehicle as described above, followed by tap water and normal chow (CE-2) for 1 week after overnight starvation.

After being sacrificed humanely with deep anesthesia and weighed (at day 7), the entire esophagus was removed, and blood samples $(2 \mathrm{~mL})$ were obtained by cardiac puncture with $24 \mathrm{G}$ needles and 2-mL sterile syringes (Terumo). The blood samples were centrifuged at $1,600 \mathrm{~g}$ for 15 minutes at room temperature and the collected supernatants were stored until use at $-80^{\circ} \mathrm{C}$. After the photo images of the luminal surface of the esophagus were captured by a digital camera (Olympus E-330; Olympus, Tokyo, Japan), the resected esophagus was divided longitudinally into 2 parts. One part was immersed immediately in liquid nitrogen and stored at $-80^{\circ} \mathrm{C}$ until protein and RNA extraction, and the other part was fixed in $10 \%$ buffered formalin to be embedded in paraffin, and then cut into $4-\mu \mathrm{m}$ thick sections. The tissue sections were stained with hematoxylin and eosin (H\&E) for light microscopic evaluation.

\section{Morphological analysis}

The damaged areas of the esophageal surface, such as erosions and ulcerations, were measured in each sample of the digital photo images using ImageJ software (https://imagej.nih.gov/ij/index.html), and the values were calculated as the proportion (\%) to the whole esophageal area. The levels of esophageal injury were macroscopically evaluated by two investigators (TM and KA) according to our previous study (Endo et al. 2010) as the inflammation score: no apparent esophageal injury as normal (Score 0 ); edema or hyperplasia without epithelial defects (Score 1); multiple erosions with hematins attached (Score 2); linear ulcerations with yellowish exudates (Score 3); and hemorrhagic coalesced ulcerations (Score 4).

\section{Immunohistochemistry (IHC)}

The dewaxed and rehydrated tissue sections were blocked for endogenous peroxidase activity in 3\% hydrogen peroxide in methanol for $10 \mathrm{~min}$, followed by antigen retrieval with a target retrieval solution (Dako, Glostrup, Denmark) done by pressure cooking at $125^{\circ} \mathrm{C}$ for $10 \mathrm{~min}$. The tissue sections were incubated with primary antibodies (Table 1 ) at $4^{\circ} \mathrm{C}$ overnight. After color development using a simple stain mouse MAX-PO (Nichirei Bioscience, Tokyo, Japan) and a DAB chromogen kit (DAKO), the tissues were counterstained with hematoxylin. The cells with $\mathrm{CD} 3$ staining were counted in 3 repre- 
Table 1. Antibodies, their commercial sources and dilutions in immunohistochemistry and western blot analysis.

\begin{tabular}{llll}
\hline Antibodies & $\begin{array}{c}\text { Source information } \\
\text { (cat\#, vender) }\end{array}$ & Dosage & Usage \\
\hline CD3 & \#sc20047, Santa Cruz & $\begin{array}{l}1: 100 \text { dilution } \\
1: 1000 \text { dilution }\end{array}$ & $\begin{array}{l}\text { IHC } \\
\text { WB }\end{array}$ \\
\hline F4/80 & \#sc377009, Santa Cruz & $\begin{array}{l}1: 100 \text { dilution } \\
1: 1000 \text { dilution }\end{array}$ & $\begin{array}{l}\text { IHC } \\
\text { WB }\end{array}$ \\
\hline STAT3 & \#4904, Cell Signaling & $1: 2000$ dilution & WB \\
\hline phosph-STAT3 (Try705) & \#9145, Cell Signaling & $1: 1000$ dilution & WB \\
\hline AKT & \#9272, Cell Signaling & $1: 2000$ dilution & WB \\
\hline Phospho-AKT (Ser 473) & \#9271, Cell Signaling & $1: 1000$ dilution & WB \\
\hline GAPDH & $\# 2118$, Cell Signaling & $1: 5000$ dilution & WB
\end{tabular}

IHC, immunohistochemistry; WB, western blotting.

sentative non-overlapping high power fields (HPFs) at $\times 400$ magnification in a blind manner.

\section{Protein extraction}

The esophageal tissues of the rats were homogenized using a rotor homogenizer and a sonicator in ice-cold Cell Extraction Buffer (Thermo Fisher Scientific, Waltham, MA, USA) containing $1 \mu \mathrm{M}$ PMSF and protease inhibitor cocktail (Sigma-Aldrich, St. Louis, MO, USA). The homogenates were centrifuged at $12,000 \mathrm{~g}$ for $15 \mathrm{~min}$ at $4^{\circ} \mathrm{C}$ and the supernatants were collected as the protein samples. The protein concentration was measured using a BCA protein assay Kit (Thermo Fisher Scientific).

\section{Enzyme linked immuno-sorbent assay (ELISA)}

The serum samples were prepared for the measurement of the leptin concentration using the Rat Leptin ELISA Kit (Yanaihara Institute, Shizuoka, Japan). The esophageal tissue proteins were processed using ELISA commercial kits for rat TNF- $\alpha$, IL- $1 \beta$, IL-6 (Thermo Fisher Scientific) and MIF (CUSABIO, Wuhan, China), according to the manufacturer's instructions. Values were expressed as concentration per milligram protein.

\section{Western blot analysis}

The extracted proteins were separated by Novex NuPAGE 4-12\% Bis-Tris Gels (Thermo Fisher Scientific) and transferred to a PVDF membrane. The membrane was incubated with primary antibodies (Table 1) overnight at $4{ }^{\circ} \mathrm{C}$, followed by incubation with antirabbit or anti-mouse IgG secondary antibody (Cell Signaling Technology, Beverly, MA, USA). An enhanced chemiluminescence detection system (SuperSignal $^{\mathrm{TM}}$ West Pico Chemiluminescent Substrate; Thermo Fisher Scientific) was used for visualizing the protein expression. Rabbit anti-glyceraldehyde-3-phosphate dehydrogenase (GAPDH) antibody (Cell Signaling Technology) was used as the loading control. Densitometric analysis was performed using ImageJ software.

\section{$R N A$ isolation and quantitative real-time polymerase chain reaction}

TRIzol reagent (Thermo Fisher Scientific) was used for the total RNA isolation from the esophageal tissues in rats according to the manufacturer's instructions. Reverse transcription was performed using the SuperScript $\mathrm{t}^{\circledR}$ VILO $^{\mathrm{TM}} \mathrm{cDNA}$ Synthesis kit (Thermo Fisher Scientific). Quantitative real-time polymerase chain reaction was carried out with the StepOnePlus Real-Time PCR System (Applied Biosystems, Carlsbad, CA, USA) and SYBR green I (PowerSYBR Green PCR Master Mix; Applied Biosystems). The expression of $\mathrm{Ob}-\mathrm{Rb}$ mRNA was confirmed by melting curve analyses, according to a previous study (Purdham et al. 2004). The primer sequences for Ob-Rb are 5'-TGACCACTCCAGATTCCACA-3' (forward) and 5'-CCACTGTTTTCACGTTGCTG-3' (reverse), and for $\beta$-actin are 5'-CCCTGGCTCCTAGCACCATG-3' (forward) and 5'-AGAGCC ACCAATCCACACAGA-3' (reverse) as the internal control.

\section{Data analysis}

Data are shown as mean \pm SD. Experiments were performed at least twice and similar results were obtained. Statistical analysis was performed using one way analysis of variance (ANOVA) followed by the Student $t$-test with JMP 12.2 Pro for Windows statistical software package (SAS Institute, Cary, NC, USA). For multiple comparison, Tukey-Kramer test was used following ANOVA. p values $<0.05$ were considered significant for all analyses.

\section{Results}

Elevated levels of leptin aggravate the reflux esophagitis in rats

The administration of leptin with the subcutaneously implanted osmotic pump system significantly increased the levels of serum leptin in the rats with reflux esophagitis $(0.3$ $\pm 0.06 \mathrm{ng} / \mathrm{mL}$ vs. $0.006 \pm 0.001 \mathrm{ng} / \mathrm{mL}$; presence vs. absence of leptin, $\mathrm{p}<0.05$ ) (Table 2). The food intake was slightly decreased in the rats with the reflux-induction surgery in the presence of leptin compared to the absence of leptin $(2.4 \pm 2.1 \mathrm{~g} / 100 \mathrm{~g}-\mathrm{BW}$ vs. $3.9 \pm 2.8 \mathrm{~g} / 100 \mathrm{~g}-\mathrm{BW}$; presence vs. absence of leptin, not significant), but no significant difference was observed in the body weight at the end of the experiment (at day 7) between two groups (242 \pm $25 \mathrm{~g}$ vs. $249 \pm 30 \mathrm{~g}$; presence vs. absence of leptin, not significant).

In the macroscopic findings, the infusion of leptin (0.6 $\mathrm{mg} / \mathrm{Kg} /$ day) for 7 days did not alter the morphological 
Table 2. Serum leptin levels and changes in body weight and food consumption of the rat reflux esophagitis with or without leptin administration.

\begin{tabular}{|c|c|c|c|c|c|c|}
\hline & \multirow{2}{*}{ Number } & \multirow{2}{*}{$\begin{array}{l}\text { Serum leptin concentration } \\
\qquad(\mathrm{ng} / \mathrm{mL})\end{array}$} & \multicolumn{2}{|c|}{ BW (g) } & \multicolumn{2}{|c|}{ Intake (100 g-BW/day) } \\
\hline & & & Day 0 & Day 7 & Diet (g) & Water $(\mathrm{mL})$ \\
\hline Leptin - & 6 & $0.006 \pm 0.001$ & $277 \pm 30^{\mathrm{a}}$ & $249 \pm 30^{b}$ & $3.9 \pm 2.8^{c}$ & $4.1 \pm 3.5^{\mathrm{d}}$ \\
\hline Leptin + & 7 & $0.3 \pm 0.06^{*}$ & $273 \pm 21^{a}$ & $242 \pm 25^{b}$ & $2.4 \pm 2.1^{c}$ & $4.1 \pm 2.4^{d}$ \\
\hline
\end{tabular}

After determining the body weight (at day 0), the rats with the surgically induced reflux esophagitis were subjected to subcutaneous implantation of an osmotic pump containing leptin (a daily dose of $0.6 \mathrm{mg} / \mathrm{Kg}$-weight) or vehicle for 1 week. The food intake and water consumption were monitored and the daily volume is expressed per $100 \mathrm{~g}$-BW. At day 7, the rats were sacrificed and blood samples were obtained to measure serum leptin concentration.

BW, body weight.

$* \mathrm{p}<0.05$.

a,b,c,dEach pair represents not significant.

appearance of the sham rats (data not shown). The reflux esophagitis in the presence of leptin showed extensive deep esophageal ulcers in almost all the rats, whereas only a few scattered superficial erosions were observed in the esophageal surface in the absence of leptin (Fig. 1A). The quantification analysis revealed a significant increase in the esophageal damage area and the macroscopic inflammation score in the presence of leptin compared with the absence of the leptin (Fig. 1B).

Leptin enhances the infiltration of $C D 3+T$ lymphocytes to the esophagus in the rats with reflux esophagitis

In the microscopic findings, as with the result of the morphological appearance, the administration of leptin to sham rats caused no histological changes or migration of inflammatory cells (Fig. 2A, B). The rats with refluxinduction surgery demonstrated mild hyperplasia of the squamous epithelium and lamia propria, and the infiltration of scattered mononuclear cells under the esophageal epithelium (Fig. 2C). In contrast, the administration of leptin to the rats with reflux-induction surgery caused extensive deficiencies in the epithelial cells, broad ulcerations with granulomatous tissue and severe infiltration of the inflammatory cells, in which mononuclear cells were predominant (Fig. 2D). By contrast, polymorphonuclear cells were seldom detected in the reflux esophagitis and were sparse even with the leptin administration.

The immunohistochemical analysis revealed that the infiltrating mononuclear cells into the esophagus showed CD3 staining (Fig. 2E, F). The infiltration of mononuclear cells with $\mathrm{CD} 3$ staining was evident in the reflux esophagitis with the administration of leptin. The quantification analysis revealed a significant increase in the CD3+ cells in the presence of leptin compared to the absence of leptin (Fig. 3A). Moreover, the Western blot analysis of the esophageal tissues demonstrated that the administration of leptin increased the $\mathrm{CD} 3$ protein levels in the reflux esopha-
A

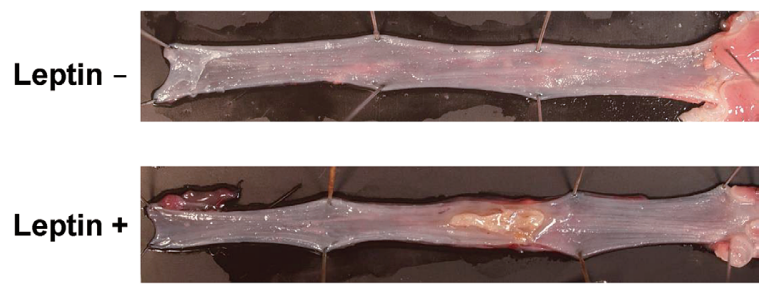

B
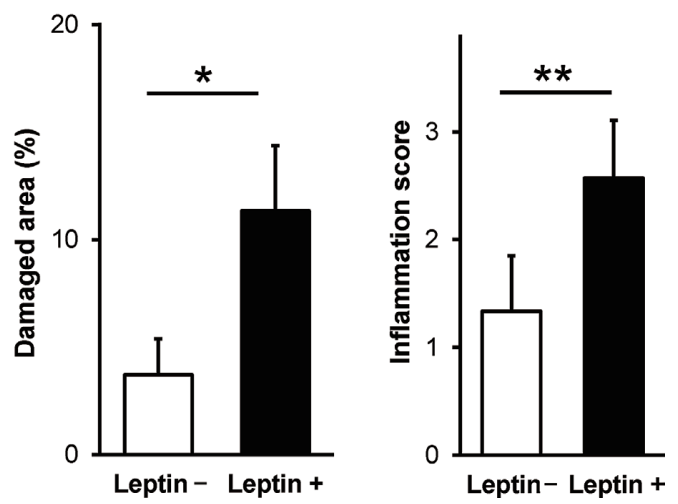

Fig. 1. The rat model of reflux esophagitis.

(A) Macroscopic appearance of the reflux esophagitis established in the rat. After the surgical induction of gastroesophageal reflux with administration of vehicle (Leptin -) or leptin (Leptin +) using an osmotic pump, rats were provided with tap water and normal chow for 1 week.

(B) Quantitative analysis of the macroscopically damaged area $(\%)$ in the whole resected esophagus and the inflammation score $(\mathrm{n}=6-7 ; *, * * \mathrm{p}<0.05)$.

gitis (Fig. 3B, C). On the other hand, leptin has been reported to activate macrophages, a phenomenon associated with obesity-related diseases (Lane 1979). However, F4/80-positive cells resided sparsely in the damaged esophageal mucosa regardless of the administration of leptin (data not shown). The Western blot analysis showed that increased levels of leptin did not influence the esophageal 
Sham

\section{H\&E}

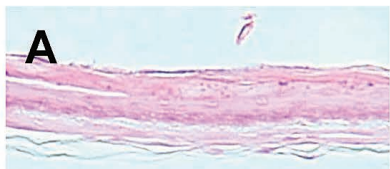

Leptin -

Leptin +

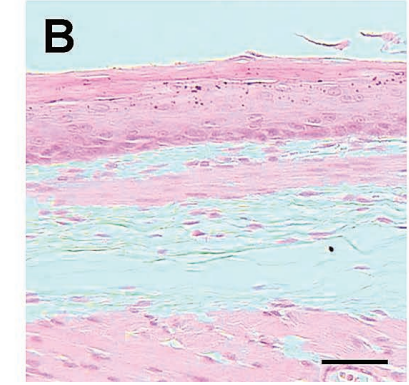

Reflux esophagitis

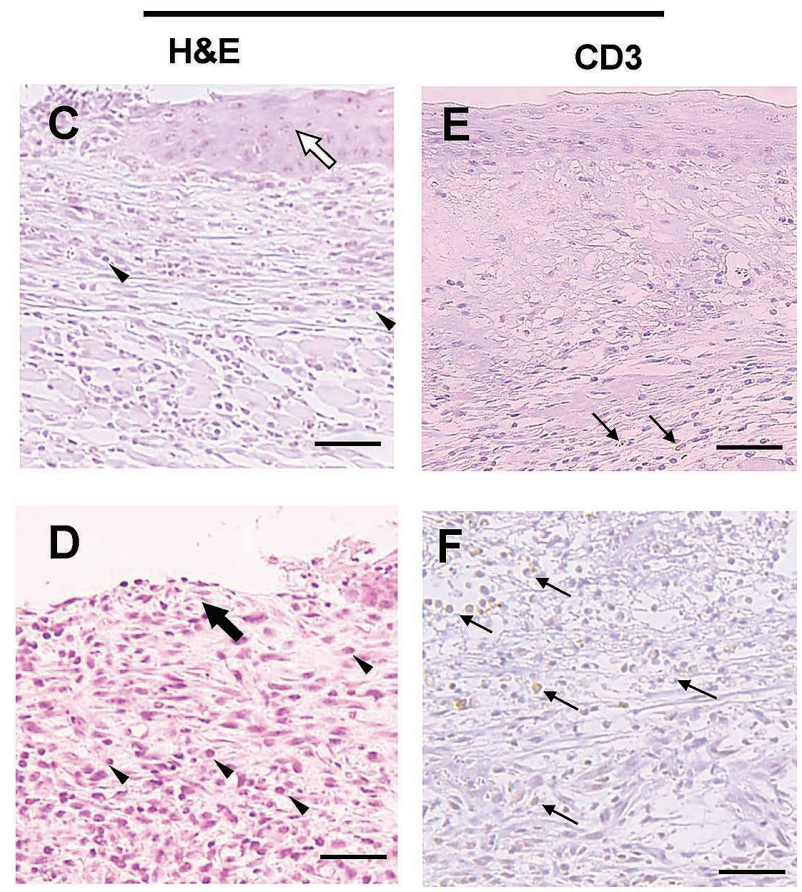

Fig. 2. Microscopic appearance of the reflux esophagitis established in the rat.

(A) and (B) Representative photomicrographs of the esophageal tissue sections, prepared from the sham-operated rats in the absence of leptin (Leptin -) and in the presence of leptin (Leptin +), respectively. The tissue sections were stained with $\mathrm{H} \& \mathrm{E}$. Bar indicates $50 \mu \mathrm{m}$.

(C) and (D) Representative photomicrographs of the esophageal tissue sections stained with H\&E, prepared from rats with reflux esophagitis in the absence of leptin (C) and the presence of leptin (D), respectively. Mild hyperplasia of squamous epithelium (open arrow in C) and broad ulcer with granulomatous tissue (bold arrow in D) are detected. Arrowheads indicate infiltrated mononuclear cells in C and D. Bar indicates $50 \mu \mathrm{m}$.

(E) and (F) Immunohistochemical analysis for CD3 expression in the esophageal tissue sections, prepared from rats with the reflux esophagitis in the absence of leptin $(\mathrm{E})$ and in the presence of leptin (F). Arrows indicate CD3-positive mononuclear cells. Bar indicates $50 \mu \mathrm{m}$.

A

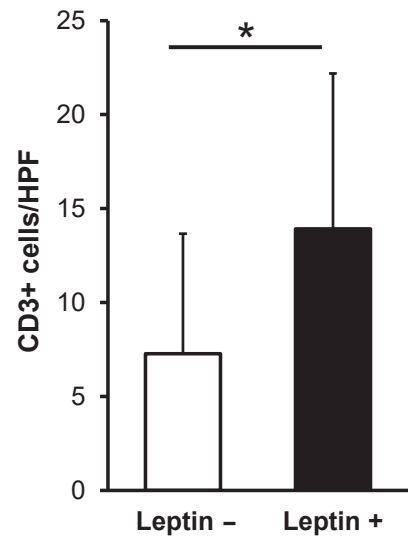

B

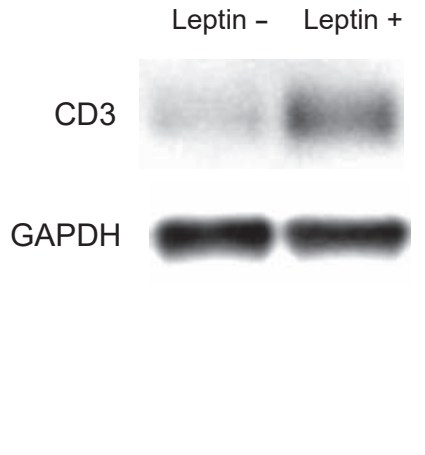

C

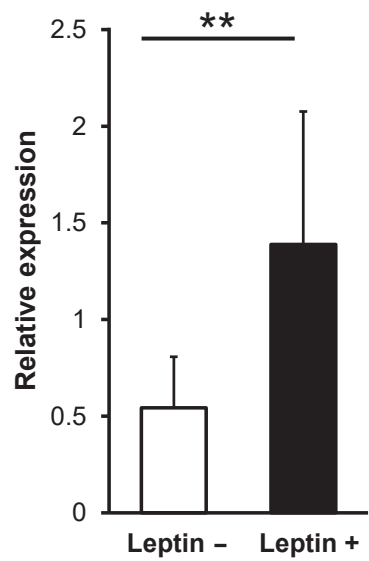

Fig. 3. Esophageal tissue expression of $\mathrm{CD} 3$ in the rat with reflux esophagitis.

(A) Infiltration of CD3 + cells in reflux esophagitis with or without leptin administration. Cells positive for CD3 were counted in 3 random high-power fields (magnification $\times 400)(n=5 ; *<0.05)$.

(B) A representative Western blot of esophageal CD3 expression in the reflux esophagitis rats with or without leptin administration.

(C) Quantified esophageal CD3 protein levels calculated as the relative expression to GAPDH by densitometry analysis in the presence or absence of the leptin $(n=5-6 ; * * p<0.05)$. 
tissue F4/80 protein levels (data not shown).

\section{MIF}

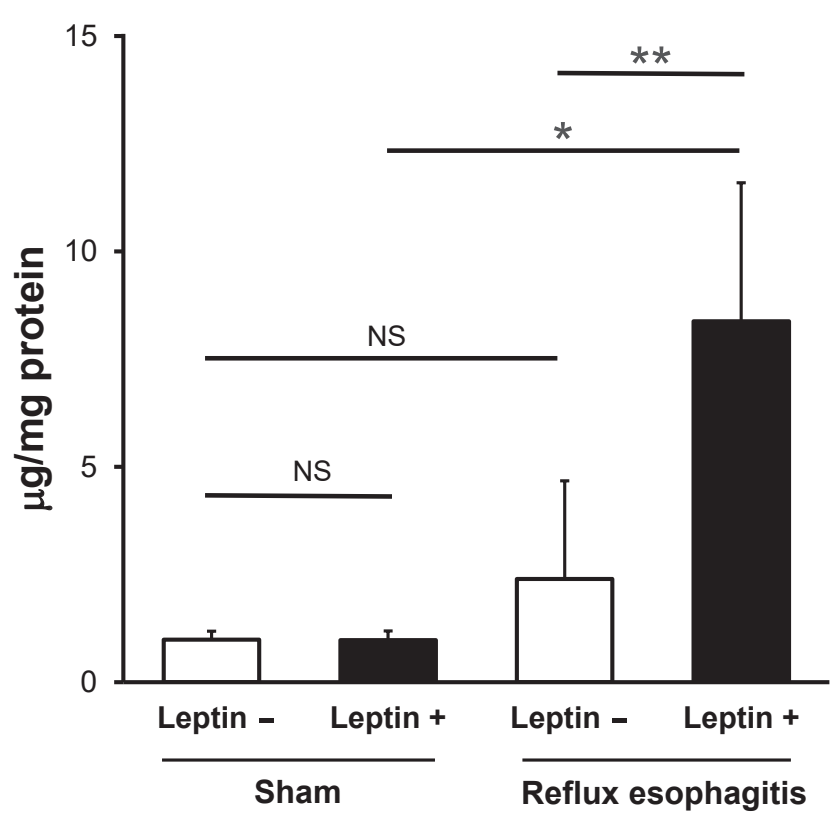

Fig. 4. Esophageal tissue concentrations of MIF in rats with reflux esophagitis.

The esophageal tissue protein samples were collected from the surgically induced rat reflux esophagitis model and sham rats with 1 -week treatment of leptin or vehicle ( $\mathrm{n}=6 ; * * * \mathrm{p}<0.05$, Tukey-Kramer test).

NS, not significant.
Leptin increases esophageal tissue levels of MIF in the rats with reflux esophagitis

The administration of leptin caused an increase in the esophageal tissue MIF protein levels in the reflux esophagitis model, while it did not alter the MIF levels in the esophageal tissues in the sham rats (Fig. 4). In the absence of leptin, the reflux induction surgery slightly increased the esophageal tissue MIF protein levels compared to the sham rats, while it significantly increased the MIF levels in the presence of leptin.

Leptin is involved in increased esophageal tissue proinflammatory cytokines in the reflux esophagitis

MIF is an upstream pro-inflammatory regulator that is involved in the production of TNF- $\alpha$, IL- $1 \beta$ and IL-6 (Chuang et al. 2010). Moreover, increased levels of these cytokines mediate the inflammatory response, which is responsible for the reflux-induced esophageal damage (Masaka et al. 2013). Corresponding to these findings, the administration of leptin caused an increase in the esophageal tissue TNF- $\alpha$, IL- $1 \beta$ and IL- 6 protein levels in the reflux esophagitis in rats (Fig. 5).

Activation of STAT3 and AKT by leptin is involved in the aggravation of reflux esophagitis

To examine the leptin-induced signal transduction, we first measured the esophageal tissue mRNA levels of $\mathrm{Ob}-\mathrm{Rb}$, a primary cell signaling receptor of leptin (PazFilho et al. 2012). The melting curve analyses in qPCR revealed the esophageal expression of $\mathrm{Ob}-\mathrm{Rb} \mathrm{mRNA}$ in the sham rats as well as the rats with the reflux esophagitis (data not shown). Additionally, the increased levels of leptin did
A

TNF- $\alpha$

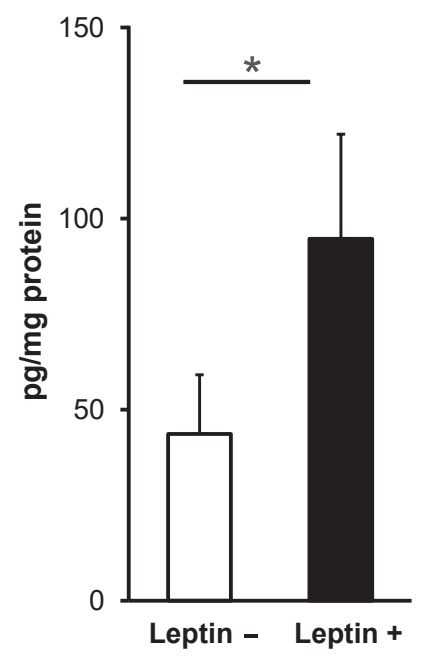

B

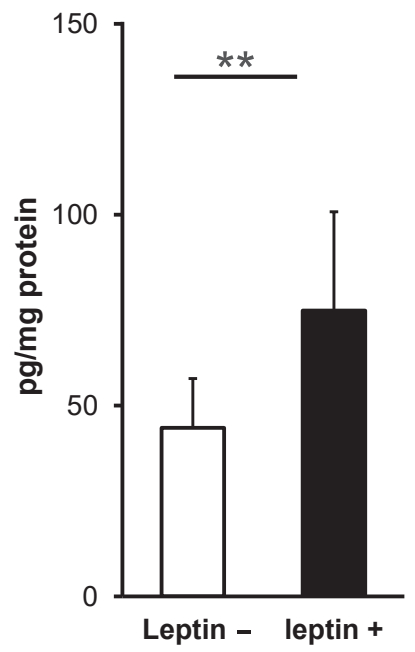

IL-6

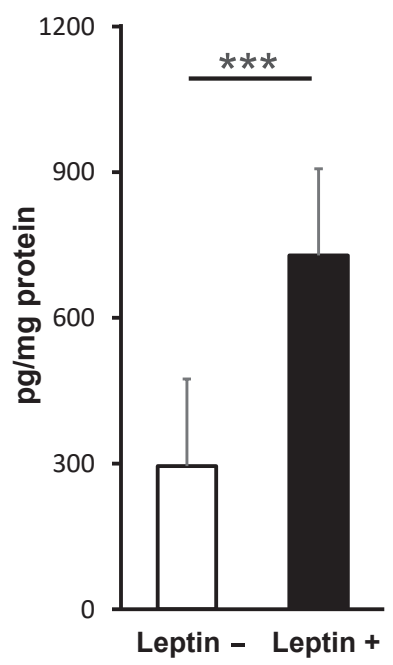

Fig. 5. Pro-inflammatory cytokine levels in the esophageal tissues of reflux esophagitis.

The esophageal tissue protein samples were collected from the model with 1-week treatment of leptin or vehicle. The tissue expression levels of TNF- $\alpha$ (A), IL-1 $\beta$ (B), IL-6 (C) were measured using ELISA ( $\mathrm{n}=5-6 ; * * * * * * * \mathrm{p}<0.05)$. 
A

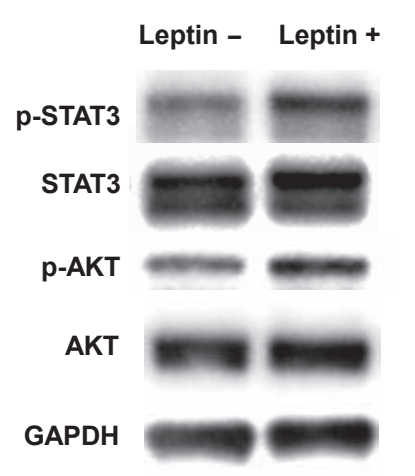

B

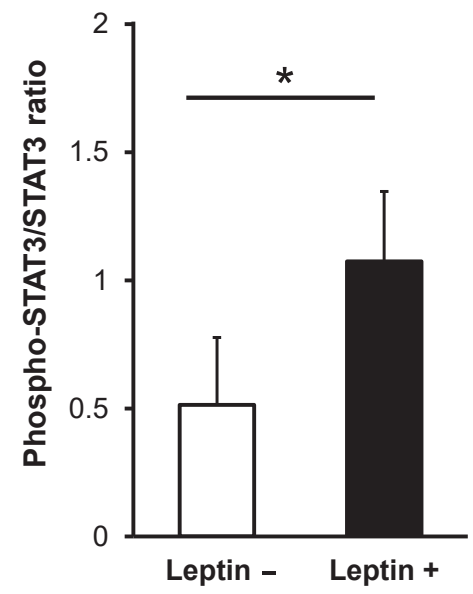

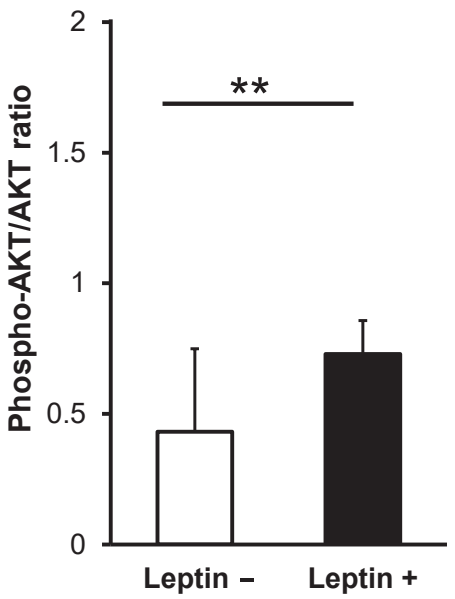

Fig. 6. The STAT3 and AKT signaling pathways in the esophageal tissues of reflux esophagitis.

(A) Representative Western blot analysis for the protein expression of phospho-STAT3, STAT3, phospho-AKT and AKT in the rat esophageal tissue of the reflux esophagitis with 1-week treatment of leptin or vehicle. The expression of GAPDH was used for the loading control.

(B) Quantified esophageal tissue protein levels of phospho-STAT3 and phospho-AKT in the rat reflux esophagitis with or without the leptin administration, calculated as the relative expression levels to STAT3 or AKT expression $(n=5-6$; $* * * \mathrm{p}<0.05)$.

not influence the expression levels of Ob-Rb mRNA in the reflux esophagitis $(4.5 \pm 5.1$ vs. $5.6 \pm 6.0$; absence vs. presence of leptin, $p=0.2$ ). The Western blot analysis revealed that the administration of leptin caused a significant increase in the protein levels of phospho-STAT3 and phospho-AKT in the esophageal tissues of rats with reflux esophagitis (Fig. 6).

\section{Discussion}

The current study demonstrated that increased levels of leptin apparently exacerbate reflux esophagitis in rats, and was associated with the increased infiltration of $\mathrm{CD} 3+$ $\mathrm{T}$ lymphocytes and MIF protein levels. In this condition, the increase in the esophageal tissue TNF- $\alpha$, IL- $1 \beta$ and IL-6 protein levels were accompanied by the increased induction of STAT3 and AKT signal pathways. These results suggest the involvement of leptin in the enhancement of the refluxinduced esophageal inflammation.

Leptin decreases food intake and up-regulates energy consumption by activating neurons in the hypothalamus, leading to weight loss and the prevention of fat accumulation (Morton et al. 2006). Additionally, nutrition influences the immune responses (Lord et al. 1998). The administration of leptin in the current study indeed increased the serum leptin levels, but there was no significant difference in the body weight and food consumption, indicating that the metabolic condition of the rats did not influence the epithelial damage caused by the surgically induced reflux esophagitis.

The current study demonstrated that the apparent infil- tration of $\mathrm{CD} 3+\mathrm{T}$ lymphocytes into the esophagus was associated with the aggravation of esophageal inflammation by leptin. This finding is supported by a previous study using a rat model demonstrating that $\mathrm{CD} 3+\mathrm{T}$ lymphocytes infiltrated to the esophagus in early phase of the refluxinduced esophageal inflammation and predominantly increased according to the progression of the inflammation (Souza et al. 2009). Therefore, the increased levels of leptin are likely to potentiate the infiltration of the T lymphocytes into the esophagus, contributing to the development of the esophageal damage.

Leptin fully activates the intracellular signaling by binding to $\mathrm{Ob}-\mathrm{Rb}$, leading to an increase in cell signaling molecules, such as phospho-STAT3 and phospho-AKT (Iikuni et al. 2008). Moreover, the expression of $\mathrm{Ob}-\mathrm{Rb}$ was observed in epithelial cells as well as immune cells including lymphocytes, which are associated with host defense mechanisms (Iikuni et al. 2008). In the current study, we showed that the exacerbation of reflux esophagitis caused by leptin was associated with the induction of STAT 3 and AKT signaling pathways. In addition, the esophageal tissue expression of $\mathrm{Ob}-\mathrm{Rb}$ mRNA was observed; namely, $\mathrm{Ob}-\mathrm{Rb}$ could be involved in the signaling induction of leptin.

In the present study, the leptin did not cause any morphological or histological changes nor differences in esophageal MIF protein levels in the sham rats, while it caused an apparent aggravation of esophageal damage and an increase in the tissue MIF levels in the rat with reflux esophagitis. Previous studies demonstrated that leptin directly activates 
T lymphocytes and the secretion of MIF (Busso et al. 2002; Calandra and Roger 2003). Some studies indicated that AKT signaling pathways promote transcription of MIF through activation of CREB (cAMP response element binding protein) and NF- $\kappa \mathrm{B}$ (nuclear factor-kappa B) (Du and Montminy 1998; Elsby et al. 2009; Veillat et al. 2009). Moreover, a recent study revealed that STAT3 signaling pathways up-regulated MIF production (Lai et al. 2015). These findings suggest that the administered leptin could stimulate $\mathrm{CD} 3+\mathrm{T}$ lymphocytes that predominantly infiltrated into the esophagus damaged by the gastric reflux and cause the T lymphocytes to produce MIF through the induction of STAT3 and AKT signaling.

Taken together, the present study has demonstrated the contribution of MIF to the development of esophageal inflammation that is related to leptin signaling. Reducing the inflammatory signaling induced by this mechanism could be a new approach to prevent the disease progression in GERD in the obese.

\section{Acknowledgments}

This study was supported in part by Grant-in-Aid from Japan Society for the Promotion of Science (15K08945, 15H04804).

\section{Conflict of Interest}

The authors declare no conflict of interest.

\section{References}

Barbier, M., Attoub, S., Joubert, M., Bado, A., Laboisse, C., Cherbut, C. \& Galmiche, J.P. (2001) Proinflammatory role of leptin in experimental colitis in rats benefit of cholecystokininB antagonist and beta3-agonist. Life Sci., 69, 567-580.

Busso, N., So, A., Chobaz-Peclat, V., Morard, C., Martinez-Soria, E., Talabot-Ayer, D. \& Gabay, C. (2002) Leptin signaling deficiency impairs humoral and cellular immune responses and attenuates experimental arthritis. J. Immunol., 168, 875-882.

Calandra, T. \& Roger, T. (2003) Macrophage migration inhibitory factor: a regulator of innate immunity. Nat. Rev. Immunol., $\mathbf{3}$, 791-800.

Carino, C., Olawaiye, A.B., Cherfils, S., Serikawa, T., Lynch, M.P., Rueda, B.R. \& Gonzalez, R.R. (2008) Leptin regulation of proangiogenic molecules in benign and cancerous endometrial cells. Int. J. Cancer, 123, 2782-2790.

Chua, S.C. Jr., Koutras, I.K., Han, L., Liu, S.M., Kay, J., Young, S.J., Chung, W.K. \& Leibel, R.L. (1997) Fine structure of the murine leptin receptor gene: splice site suppression is required to form two alternatively spliced transcripts. Genomics, $\mathbf{4 5}$, 264-270.

Chuang, C.C., Chuang, Y.C., Chang, W.T., Chen, C.C., Hor, L.I., Huang, A.M., Choi, P.C., Wang, C.Y., Tseng, P.C. \& Lin, C.F. (2010) Macrophage migration inhibitory factor regulates interleukin-6 production by facilitating nuclear factor-kappa B activation during Vibrio vulnificus infection. BMC Immunol., 11,50 .

Corley, D.A., Kubo, A., Levin, T.R., Block, G., Habel, L., Zhao, W., Leighton, P., Quesenberry, C., Rumore, G.J. \& Buffler, P.A. (2007) Abdominal obesity and body mass index as risk factors for Barrett's esophagus. Gastroenterology, 133, 34-41; quiz 311 .

Du, K. \& Montminy, M. (1998) CREB is a regulatory target for the protein kinase Akt/PKB. J. Biol. Chem., 273, 3237732379.

Elsby, L.M., Donn, R., Alourfi, Z., Green, L.M., Beaulieu, E. \& Ray, D.W. (2009) Hypoxia and glucocorticoid signaling converge to regulate macrophage migration inhibitory factor gene expression. Arthritis Rheum., 60, 2220-2231.

Endo, H., Iijima, K., Asanuma, K., Ara, N., Ito, H., Asano, N., Uno, K., Koike, T., Imatani, A. \& Shimosegawa, T. (2010) Exogenous luminal nitric oxide exposure accelerates columnar transformation of rat esophagus. Int. J. Cancer, 127, 20092019.

Fantuzzi, G., Sennello, J.A., Batra, A., Fedke, I., Lehr, H.A., Zeitz, M. \& Siegmund, B. (2005) Defining the role of T cell-derived leptin in the modulation of hepatic or intestinal inflammation in mice. Clin. Exp. Immunol., 142, 31-38.

Iikuni, N., Lam, Q.L., Lu, L., Matarese, G. \& La Cava, A. (2008) Leptin and inflammation. Curr. Immunol. Rev., 4, 70-79.

Kendall, B.J., Macdonald, G.A., Hayward, N.K., Prins, J.B., Brown, I., Walker, N., Pandeya, N., Green, A.C., Webb, P.M. \& Whiteman, D.C.; Study of Digestive Health (2008) Leptin and the risk of Barrett's oesophagus. Gut, 57, 448-454.

Lai, Y.C., Chuang, Y.C., Chang, C.P. \& Yeh, T.M. (2015) Macrophage migration inhibitory factor has a permissive role in concanavalin A-induced cell death of human hepatoma cells through autophagy. Cell Death Dis., 6, e2008.

Lane, D.S. (1979) Dental considerations of diabetes mellitus. Dent. Hyg. (Chic.), 53, 306-307.

Lord, G.M., Matarese, G., Howard, J.K., Baker, R.J., Bloom, S.R. \& Lechler, R.I. (1998) Leptin modulates the T-cell immune response and reverses starvation-induced immunosuppression. Nature, 394, 897-901.

Masaka, T., Iijima, K., Endo, H., Asanuma, K., Ara, N., Ishiyama, F., Asano, N., Koike, T., Imatani, A. \& Shimosegawa, T. (2013) Gender differences in oesophageal mucosal injury in a reflux oesophagitis model of rats. Gut, 62, 6-14.

Morrison, M.C. \& Kleemann, R. (2015) Role of macrophage migration inhibitory factor in obesity, insulin resistance, type 2 diabetes, and associated hepatic co-morbidities: a comprehensive review of human and rodent studies. Front. Immunol., 6, 308.

Morton, G.J., Cummings, D.E., Baskin, D.G., Barsh, G.S. \& Schwartz, M.W. (2006) Central nervous system control of food intake and body weight. Nature, 443, 289-295.

Omura, N., Kashiwagi, H., Chen, G., Suzuki, Y., Yano, F. \& Aoki, T. (1999) Establishment of surgically induced chronic acid reflux esophagitis in rats. Scand. J. Gastroenterol., 34, 948-953.

Onodera, S., Kaneda, K., Mizue, Y., Koyama, Y., Fujinaga, M. \& Nishihira, J. (2000) Macrophage migration inhibitory factor up-regulates expression of matrix metalloproteinases in synovial fibroblasts of rheumatoid arthritis. J. Biol. Chem., 275, 444-450.

Otero, M., Lago, R., Gomez, R., Dieguez, C., Lago, F., GomezReino, J. \& Gualillo, O. (2006) Towards a pro-inflammatory and immunomodulatory emerging role of leptin. Rheumatology $($ Oxford $), 45,944-950$.

Paz-Filho, G., Mastronardi, C., Franco, C.B., Wang, K.B., Wong, M.L. \& Licinio, J. (2012) Leptin: molecular mechanisms, systemic pro-inflammatory effects, and clinical implications. Arq. Bras. Endocrinol. Metabol., 56, 597-607.

Purdham, D.M., Zou, M.X., Rajapurohitam, V. \& Karmazyn, M. (2004) Rat heart is a site of leptin production and action. Am. J. Physiol. Heart Circ. Physiol., 287, H2877-2884.

Rubenstein, J.H., Morgenstern, H., McConell, D., Scheiman, J.M., Schoenfeld, P., Appelman, H., McMahon, L.F. Jr., Kao, J.Y., Metko, V., Zhang, M. \& Inadomi, J.M. (2013) Associations of diabetes mellitus, insulin, leptin, and ghrelin with gastroesophageal reflux and Barrett's esophagus. Gastroenterology, 145, 1237-1244. e1-5. 
Siegmund, B., Lehr, H.A. \& Fantuzzi, G. (2002) Leptin: a pivotal mediator of intestinal inflammation in mice. Gastroenterology, 122, 2011-2025.

Singh, P., Hoffmann, M., Wolk, R., Shamsuzzaman, A.S. \& Somers, V.K. (2007) Leptin induces C-reactive protein expression in vascular endothelial cells. Arterioscler. Thromb. Vasc. Biol., 27, e302-307.

Souza, R.F., Huo, X., Mittal, V., Schuler, C.M., Carmack, S.W., Zhang, H.Y., Zhang, X., Yu, C., Hormi-Carver, K., Genta, R.M. \& Spechler, S.J. (2009) Gastroesophageal reflux might cause esophagitis through a cytokine-mediated mechanism rather than caustic acid injury. Gastroenterology, 137, 17761784.

Spechler, S.J. \& Souza, R.F. (2014) Barrett's esophagus. N. Engl. J. Med., 371, 836-845.

Veillat, V., Lavoie, C.H., Metz, C.N., Roger, T., Labelle, Y. \&
Akoum, A. (2009) Involvement of nuclear factor-kappaB in macrophage migration inhibitory factor gene transcription up-regulation induced by interleukin-1 beta in ectopic endometrial cells. Fertil. Steril., 91, 2148-2156.

Wang, P., Yang, F.J., Du, H., Guan, Y.F., Xu, T.Y., Xu, X.W., Su, D.F. \& Miao, C.Y. (2011) Involvement of leptin receptor long isoform (LepRb)-STAT3 signaling pathway in brain fat massand obesity-associated (FTO) downregulation during energy restriction. Mol. Med., 17, 523-532.

Yarandi, S.S., Hebbar, G., Sauer, C.G., Cole, C.R. \& Ziegler, T.R. (2011) Diverse roles of leptin in the gastrointestinal tract: modulation of motility, absorption, growth, and inflammation. Nutrition, 27, 269-275.

Zhang, Y., Proenca, R., Maffei, M., Barone, M., Leopold, L. \& Friedman, J.M. (1994) Positional cloning of the mouse obese gene and its human homologue. Nature, 372, 425-432. 